\title{
LACAN CON HUXLEY O EL DRAMA HISTÓRICO- TEMPORAL DE LA FETALIZACIÓN
}

\author{
Manuel Coloma \\ École lacanienne de psychanalyse \\ Viña del Mar, Chile \\ mcol520@gmail.com
}

\section{RESUMEN / ABSTRACT}

La relación de Lacan con Huxley es casi desconocida. Sin embargo, existe un indicio que permite entrever la recepción en el psicoanalista de algún tipo de influencia recibida del escritor. Con el recurso de la verosimilitud del intercambio, a partir de una sola mención de Lacan a Huxley, intentaremos despejar una de las líneas más herméticas de la versión de 1949 del "El estadio del espejo", la que hace referencia a los efectos de la fetalización. Siendo esta condición una temática común entre ambos autores, el aspecto dramático del estadio del espejo - proyectado en historia subjetiva- podría llegar a captarse con una versión novelada del retardo en el desarrollo humano.

PALABRAS ClaVE: fetalización, drama, historia, tiempo, ficción.

\section{LACAN WITH HUXLEY OR THE HISTORICAL-TEMPORAL DRAMA OF FETALIZATION}

Lacan's relationship with Huxley is almost unknown. However, there is an indication that allows us to glimpse the reception in the psychoanalyst of some type of influence received from the writer. Using the verisimilitude of the exchange, from a single mention by Lacan to Huxley, we will try to clear one of the most hermetic lines of the 1949 version of "The Mirror Stadium", which refers to the effects of the fetalization. As this condition is a common theme between both authors, the dramatic aspect of the mirror stage-projected in subjective historycould come to be captured with a fictionalized version of the delay in human development.

KEYWORDS: fetalization, drama, history, time, fiction.

Recepción: 30/11/2020

Aprobación: 28/12/2020 
Cuando George Didi-Huberman se encontró con los cuadros de colores en la parte inferior de la "Virgen de las sombras" de Fra Angélico, quedó cautivado por el problema temporal implicado en ellos (Ante el tiempo 31-32). Fue ahí que comenzó una reflexión en torno al papel del anacronismo -tan temido por los historiadores-y sus posibles acepciones. Por una parte, el error: proyectar categorías del presente en un pasado que debería mantenerse puro para que emerja su real significado (36); por otra, conducir a lo que una obra como la de Angélico obligaba: explicar un objeto perfectamente visible pero que hasta ese momento no había sido "ni mirado, ni interpretado, ni incluso entrevisto en la inmensa literatura científica consagrada a la pintura del Renacimiento" (33).

Dar cuenta de ese objeto debía hacerse entonces, considerando una cierta "necesidad del anacronismo" (38). Y es que podría decirse que los cuadros "abstractos" de Fra Angélico "recuerdan" por ejemplo, a los trabajos de Pollock (44). Sin embargo, este anacronismo, este diferencial de tiempo (40), no debe arrojar a expectativas seudomórficas ni a conclusiones apresuradas en la búsqueda de un antecesor (44). Más bien, debe resaltar el valor de la incongruencia y de la inactualidad, permitiendo que se levante así un nuevo objeto y problema (44). En consecuencia, se trata de un modo temporal que manifiesta la exuberancia y sobredeterminación de la imagen (38-39), recurso necesario y fecundo cuando el pasado no alcanza para explicarse a sí mismo (42-43).

Se vuelve necesario considerar acá lo que entendemos por "anacronismo". Y es que, a falta de abordaje filológico, puede llegar a pensarse que algunas nociones de Lacan contienen total novedad, borrando de paso las opciones de la genealogía y aplicando entonces, categorías del presente a supervivientes sutilezas del pasado; pero por otra parte, también ha llegado a condenarse al anacronismo -en el sentido de lo "anticuado" (39)- a textos y momentos tempranos que sin embargo pueden llevar en ellos una riqueza impensada. Bajo la primera consideración, vemos que hay una utilidad en evitar la proyección anacrónica, aunque a riesgo de que, a fuerza de mantenernos en ese exclusivo nivel, se vuelvan invisibles objetos que pese a todo se encuentran a la vista y ameritan sumar una nueva capa de análisis. Un estrato así aparece con la segunda definición, donde el anacronismo como abordaje de la enseñanza de Lacan no solo ameritaría ser rescatado, sino considerado casi al mismo modo en que, según Didi-Huberman, este logra devolverle a la imagen una temporalidad que "no será reconocida como tal en tanto el elemento histórico 
que la produce no se vea dialectizado por el elemento anacrónico que la atraviesa" (48-49).

Creemos que es algo de este orden lo que ocurre con la relación entre Lacan y Huxley. Ella misma es prácticamente desconocida. Sin embargo, las inquietudes al respecto comienzan ante todo a partir de una pequeña mención que Lacan realiza el 19 de junio de 1963 durante su seminario La angustia (1962-63) donde lo llama "mi amigo" ("mon ami"1). No hemos podido corroborar si dicha amistad existió realmente o si Lacan ocupa el término como una manifestación de afecto o incluso de gusto personal por sus escritos. La mención cobra un valor inesperado si consideramos que Huxley moriría pronto, el 22 de noviembre de 1963. El hecho es que en aquella sesión de seminario Lacan da vueltas alrededor de las heces; las considera formas del objeto $a$ y el despliegue argumentativo toma vías que podrían considerarse onto-filogenéticas. El desfile de animales es notorio puesto que la relación de algunos de éstos con sus propias heces nos enseña respecto a la delimitación del espacio y el territorio, fronteras difusas bajo la "sensación" de la angustia (6-7, 16-17). Lacan recuerda entonces la obra Adonis y el alfabeto, “....un librito admirable, como muchos otros de mi amigo Aldous Huxley "2" (10), donde se reúnen diversos escritos cortos. El libro fue publicado en Norteamérica como Tomorrow, tomorrow and tomorrow, nombre de uno de los ensayos de la recopilación, y aunque existen ediciones con el título Adonis and the alphabet en el resto del mundo se dio a conocer como Adonis y el alfabeto (Huxley 1958). El texto al que se refiere Lacan sin explicitarlo es Hiperión para un sátiro, que vendría a ser una buena ilustración de las dificultades y peripecias que experimenta el hombre respecto a sus excrementos a través de una organización fabril que los recupera para producir riqueza (La angustia 10). Nos comenta además la anécdota de que su copia del libro se ha perdido, "como el excremento" (10). Es en este contexto referencial que sobreviene no solo la declaración de amistad sino también la admiración por muchos otros de sus libros (10).

Por supuesto, también habríamos podido comenzar con la mención que Lacan hace de Huxley el 5 de febrero de 1958 en el marco del seminario Las

\footnotetext{
La estenotipia confirma el uso del término. Puede consultarse en la página de la École lacanienne de psychanalyse: http://ecole-lacanienne.net/wp-content/uploads/2016/04/1963.06.19. pdf

Las cursivas son nuestras.
} 
formaciones del inconsciente (1957-1958). Pero esta no dice nada acerca de una relación de cercanía o influencia mutua; sin embargo, sí contiene algo que se corresponde con el ánimo de nuestro texto, puesto que Lacan alude a la importancia de considerar lo que un novelista puede enseñarnos sobre el carácter propiamente humano del mundo en la figura de una chica que busca hacerse fustigar (142-143). Huxley habría producido una ficción que nos permite abordar analíticamente las imágenes del látigo y el azote, ligadas según Lacan, tanto a la perversión como a la humanidad misma. La referencia es la conocida obra Un mundo feliz (2003).

Pero la inquietud persiste: si son amigos, ¿podríamos encontrar la presencia de otras obras de Huxley esparcidas anteriormente en la enseñanza de Lacan? Y si no lo son, la estima indudable que Lacan manifiesta podría reenviarnos a la misma pregunta. Como sea, se trata de una declaración de cercanía de la cual podemos suponer un estar al tanto, o si se quiere, un saber. Por un efecto de atracción, estos agujeros biográficos conducen a la posibilidad de ficcionar un fragmento de historia a partir de datos reales y de lo cual podríamos esperar resultados que durante un lapso de tiempo investigativo se mantendrían inciertos. El conejo blanco de las referencias nos ha llevado a la búsqueda por representar una realidad posible, esa que Ginzburg proponía, en el comienzo de El hilo y las huellas, como el vínculo que borraba las diferencias entre narraciones de ficción y narraciones históricas, entendiéndolas bajo el cielo común de una "disputa por la representación de la realidad" (12). Si consideramos que Lacan no había mencionado una amistad con Huxley hasta la sesión de $L a$ angustia, emprender una construcción en torno a ambos autores implica por fuerza a una "narrativa histórica", reconstrucción fantasiosa incluso, pero no por eso "falsa", sino ante todo, verosímil. Al respecto, tal vez más allá de proceder con "huellas", lo que podría interesarnos es el material ofrecido por la borradura de las mismas, borradura del signo respecto de la cosa, es decir, la acción que define al significante según Lacan (L'identification 45-46).

Todo el problema gira alrededor de esa "presencia" de Huxley en Lacan: clara y explícita para el caso del seminario de La angustia, pero incierta o desconocida para momentos anteriores. Y es que el punto de conexión comienza a abrirse camino por la cercanía de Huxley con las temáticas evolutivas, un material que sirvió como documentación para sus obras, recibiendo estos datos nada menos que de su hermano, Julian Huxley, científico de alto renombre en el campo de la biología evolutiva y de las problematizaciones darwinianas de la evolución de las especies. 
Ya sabemos a dónde vamos. Sabemos con antelación que hay un concepto en común del cual Lacan extrajo beneficios; lo había mencionado varias veces hacía casi 20 años y más, antes de la lección del 19 de junio del 63. Dicho concepto reduciría su presencia posteriormente, aunque no por eso perdería relevancia. La "amistad" declarada y la admiración por "muchos" de sus otros libros parecen ir revelándose, si hemos de reunirlas en una sola imagen, como un verdadero "fósil director" (Didi-Huberman, La imagen 302-327). Este objeto-fósil nos dirige por tanto hacia una obra dedicada a las temáticas evolutivas: Viejo muere el cisne o Muere el cisne después del verano (After many a summer dies the swann) del año 1939. Por su parte un investigador como Stephen Jay Gould -paleontólogo inquieto por las problemáticas evolutivas y que recurrió constantemente a la literatura y sus ejercicios de estilo para expresar sus ideas-nos indica que dicha obra noveliza en específico un drama que gira en torno a la "fetalización", ese concepto con el cual Lacan había comenzado su periplo por lo imaginario y que había sido puesto de relieve por el anatomista Louis Bolk en la década de los 20.

De este modo, la amistad declarada de Lacan en 1964 hacia Huxley junto con la presencia de las temáticas de orden biológico-temporal que se dieron cabida en las novelas del escritor, nos conducen hacia la versión escrita del año 49 de El estadio del espejo.

\section{UNA LÍNEA DE FICCIÓN}

Luego de haberse referido a la fetalización, reconocida por los embriólogos como el dato de entrada del nacimiento del hombre en tanto prematuro, la versión del año 49 de El estadio del espejo sorprende con la siguiente afirmación: "Este desarrollo es vivido como una dialéctica temporal que proyecta decisivamente en historia la formación del individuo: el estadio del espejo es un drama cuyo empuje interno se precipita de la insuficiencia a la anticipación" (102). Ya en algunos párrafos anteriores había situado la instancia del yo (moi) en una "línea de ficción"; si consideramos entonces el dato de la fetalización, este Urbild -captado de manera inmediata y recibido con todas las características del ahá-erlebnis animal (p. 99)- no solo establece una línea ficticia que sostiene como un molde a la descoordinación y el retraso de la cría humana, sino que arroja al sujeto a un "drama" dialéctico y temporal, sucesión que sería característica del estadio del espejo. En otros términos, dicho drama bien podría constituir una ficción permanente que se constituye, nada 
menos, que en la historia del sujeto, con toda la irreductibilidad y anticipación identificatoria implicada en el yo ( $\mathrm{moi}$ ). Pero, ¿cómo entender este "drama"?, ¿por qué la fetalización podría dar cuenta tanto de una dialéctica temporal como de una historia dramática?

Conocemos la referencia al concepto ante todo por El estadio del espejo, aunque el mismo ya venía siendo presentado por Lacan desde hacía 13 años. Lo que nos queda de la primera versión del año 36 -las notas tomadas por Francoise Dolto- testimonian esta presencia (Guillerot, Dolto, Lacan y el estadio del espejo 293-300); allí, todas las dificultades humanas ligadas a la construcción de los fenómenos de expresividad, considerados como fuente de la síntesis del cuerpo propio, se basan en esta condición fetalizada: "retardo de mielinización de las neuronas inf. de la médula", "prematuración", "impotencia biológica...fragmentación de sus funciones vitales" (294-296). Al unísono, la preeminencia de la imagen del doble en el ser humano, debe concebirse como una compensación a su nacimiento prematuro (296).

La crítica que Édouard Pichon hiciera a Los complejos familiares de Lacan en el año 38, testimonia que el concepto es de relevancia en el despliegue argumentativo de dicho artículo, pese a que la reseña no logra ir más allá de un despliegue de autoridad en una especie de nueva versión del chiste del caldero agujereado de Freud: 1 . no se entiende lo que es la neotenia, 2. La entendemos pero no podemos estar de acuerdo y 3. Lacan hace grandilocuencia de un concepto que no sería más que la herencia de las lecciones escolares sobre Buffon (116-119). En otros términos, Pichon hace su crítica en este punto con lo mismo que aprendió en ... las lecciones escolares sobre Buffon. Sabemos por otra parte que en el año 1961 la Revue française de psychanalyse publicó la versión escrita de la conferencia Le problème de la genèse humaine, dictada por Bolk el 15 de abril de 1926, en la cual había presentado el grueso de sus propuestas sobre la fetalización: especie de reconocimiento tardío considerando las tempranas resonancias que el concepto tuvo en Lacan al servirse de una biología que podía estar en mayor afinidad con las exigencias de la clínica psicoanalítica.

Contamos también con las referencias esparcidas en Acerca de la causalidad psíquica ([1945], 2008) y en Algunas reflexiones sobre el yo ([1951], 2018). Las discusiones sobre aspectos presentes en las propuestas de Michael Balint durante el seminario de Los escritos técnicos de Freud (2009, 297-340) también harían referencias al retraso del nacimiento y desarrollo humano. Mucho más adelante, en la conferencia del año 74 conocida como La Tercera (2010), la fetalización sigue vigente, pese al paso de los años, 
como condición real de la entrada del cuerpo en la economía del goce (91). En todas estas menciones, el nombre de Bolk es explicitado, no así, en el texto de 1949 que nos convoca.

Si volvemos a El estadio del espejo y lo consideramos como un nudo central de los antecedentes mencionados, advertimos que el drama de la fetalización se enfatiza con nociones como "dehiscencia" (102) y "Discordia" (102), propiedades del organismo humano que se experimentarían como malestar e incoordinación motriz de los primeros meses (102). Si hemos de considerar que el estadio del espejo manifiesta una jubilosa anticipación a la insuficiencia, la dehiscencia y la discordia se presentan en dos niveles: ya de entrada en la situación corporal humana y como desgarradura entre la imagen de completitud y la realidad corporal, es decir, sutura fallida respecto a la insuficiencia original. Referencia tomada del paradigma botánico de Hegel (Baños Orellana, De cómo 8), la dehiscencia es un concepto que no solo hace referencia a una herida que habiéndose curado vuelve a abrirse, sino también a un fruto que se abre para liberar la semilla o a las anteras de una flor que esparcen el polen. Lacan no deja de servirse de ella para considerarla como una espina orgánica clavada por siempre en el hombre, enfermedad que es la condición para que la palabra encuentre su sostén en dicha hiancia (Función y campo 271; Variantes 331). Así, Lacan hace de esta carencia una potencia: "enfermedad fecunda...falta feliz de la vida" (331), discordancia que entrega a los objetos del mundo humano "su polivalencia instrumental y su polifonía simbólica" (La agresividad 116).

El énfasis en juego arroja una interpretación posible de la "dialéctica temporal que se proyecta decisivamente en historia": podemos entenderla por lo que van a ser las identificaciones sucesivas que irán constituyendo una historia, pero ¿de qué manera la fetalización actualizaría el tiempo? Tiempo e historia se conjugan en el estadio del espejo, puesto que la dialéctica entre la realidad orgánica y la imagen que la alivia deberá repetirse como efecto de la dehiscencia; a cada momento del desarrollo le corresponderá una situación donde volverá a producirse este salto desde la insuficiencia corporal a la imagen del espejo. Debido a esto, la consecuencia es algo que comienza a establecerse al nivel de la historia del sujeto, serie de identificaciones con las cuales se ha ido configurando el yo y que deben ser revisadas en análisis al mismo tiempo que se reconstruye su historia.

Pero de alguna forma, el drama sigue en pie. ¿Cómo podemos darle más "cuerpo"? A partir de los antecedentes recopilados, podremos confirmar que Lacan se encuentra muy bien informado, efecto tal vez, entre otras cosas, de la 
cercanía con Wallon. Pero también habremos de corroborar que no son detalles menores los que maneja; y es que el recurso a la biología no era un terreno por regalar, ya que a diferencia de sus colegas psicoanalistas, esta misma le serviría para oponerse tanto al predominio de la recapitulación, como a la manera en que se descartaba la existencia de la pulsión de muerte. Subrayar la incompletud del neuroeje (Acerca de 183), el inacabamiento anatómico del sistema piramidal (El estadio 102), la insuficiente mielinización del mismo que observa el histólogo (Algunas reflexiones 75), así como la presencia de remanencias humorales del organismo materno (El estadio 102) eran los datos predilectos de una prematuración especifica del nacimiento en el hombre, coincidiendo con los rasgos neoténicos retardados que los defensores de Bolk mantienen en pie contra los protectores de la recapitulación y de la llamada “evolución en mosaico" (Gould, Desde 71-74).

\section{FETALIZACIÓN-NEOTENIA-RETARDO}

El incremento de la duración vital en los individuos habría sido, para Bolk, el principal fenómeno fisiológico de la antropogénesis (Origin of racial characteristics in man 1). Así, la génesis del hombre se encontraría marcada por un desarrollo de ritmo ralentizado. Este "film retardado" (1) produce los rasgos somáticos característicos del hombre actual que lo diferencian de su ancestro pitecoide, rasgos controlados e incluso suprimidos en su evolución: he aquí el estado fetal o infantil del cuerpo humano -fetalizado-donde casi todas sus características típicas corresponderían a persistentes etapas fetales del desarrollo del resto de los primates (2).

Por su parte, uno de los más conocidos defensores de la fetalización -Stephen Jay Gould-nos describe en su breve ensayo El niño como verdadero padre del hombre (Desde Darwin 69-74) algunas de las características que compartimos con las etapas juveniles de otros primates o de los mamíferos en general y que Bolk agrupó en una lista de más de 20: "Nuestro cráneo redondeado y bulboso (sede de nuestro cerebro de mayor tamaño)" (68), "Nuestro rostro "juvenil" (perfil recto, mandíbulas y dientes pequeños y arcos ciliares débiles)" (68), "Posición del foramen magnum (el agujero de la base de nuestro cráneo del que emerge la médula espinal)" (68), "Cierre tardío de las suturas del cráneo y otras señales de calcificación retrasada del esqueleto" (69) (el punto blando de los bebés, "Así, nuestro cerebro puede continuar con su pronunciada expansión posnatal” (69)), "Dirección ventral 
del canal vaginal en las mujeres. Copulamos con mayor comodidad cara a cara porque estamos construidos así" (69), "Nuestro fuerte dedo gordo del pie, no rotado y no oponible" (69). Gould cita a Bolk en este punto para definir lo que seríamos en base a esta lista: "un feto de primate que ha alcanzado la madurez sexual" (70).

Pero un problema de mayor envergadura se nos presenta acá, y es que Bolk no habría rehusado una especie de implicación obvia, puesto que el freno hormonal podría eventualmente soltarse, lo que daría una oportunidad a los rasgos pitecoides latentes en nosotros para volverse patentes (70). Gould solo parece tomarse de este aspecto para indicar la causa que habría llevado al descrédito a las hipótesis de Bolk por basarlas exclusivamente en un freno químico-hormonal (70). Es por esto que la teoría darwiniana durante los años 30 puso un signo de interrogación al respecto, observando que "no todos nuestros rasgos están retrasados" (71), pero sobre todo, proponiendo la "evolución en mosaico", donde los "órganos evolucionan por separado en respuesta a requerimientos adaptativos diferentes" (71). Es por esto que para Gould la neotenia "debe ser justificada como un resultado esperado de procesos que actúan en la evolución humana" (71).

En principio, la propuesta de la neotenia -término con el que llegó a conocerse la fetalización - fue una forma de oponerse a la teoría de la recapitulación (ontogenia recapitula la filogenia; filogenia se repite en la ontogenia). Popularizada a fines del siglo XIX, esta teoría llevó al extremo ciertas propuestas psicoanalíticas, si bien no tan evidentes $-\mathrm{O}$ al menos abiertas a discusión- como nos las presenta Gould respecto a Freud (Ontogenia 194), marcadas para el caso de Ferenczi y su aprecio declarado por Haeckel plasmado en su libro Thálassa, donde la identificación individual al pene y a los espermatozoides ingresando a la vagina y al interior del cuerpo femenino respectivamente repiten la historia de los antepasados que lograron sobrevivir al desecamiento de los océanos (59). Para Gould, si la recapitulación fuese verdad general los rasgos tendrían que haberse acelerado durante la historia evolutiva, puesto que "los rasgos adultos de los antecesores tan sólo pueden convertirse en las etapas juveniles de sus descendientes si su desarrollo se ve acelerado" (72). Y eso es lo que no ocurre; por el contrario, las etapas adultas de los descendientes manifiestan el retardo de los rasgos juveniles de los antecesores, haciendo patentes los rasgos neoténicos (72). En este sentido, el retardo le parece a Gould un dato innegable en la historia evolutiva humana $(72,73)$ y si se consigue demostrar su presencia general en el desarrollo de la misma, la neotenia puede convertirse en algo esperable de acuerdo a 
ciertos rasgos clave; de este modo, se la saca de su dependencia a una "simple tabulación empírica" (72).

De este modo, el que los primates en general se encuentren retardados respecto a gran parte de los mamíferos, que los simios vivan más tiempo y maduren con mayor lentitud que los monos y prosimios y que en los humanos la duración y el ritmo de vida se vean aún más retardadas, corrobora esta situación de base para la evolución humana (72). Y los datos que más llaman nuestra atención en este ritmo humano ralentizado son la demora en la osificación de los huesos por una parte y el tamaño de nuestro cerebro por otra; en efecto, chimpancés y gorilas llegan al 70 por 100 del tamaño final al comenzar el primer año, en cambio nosotros alcanzamos ese valor recién a principios del tercer año (72-73).

Por su parte, Lacan también podría estar tratando de decir que si bien existe esta preeminencia del retardo como determinante de lo que ocurre en el hombre, no todo se reduce a ella, ya que su retardación lo conducirá a la preferencia, el privilegio que tiene para él, la imago del otro, la imagen ante el espejo a la cual se identifica en una alienación fundamental. Podemos ver en efecto, de cuántas maneras el hombre vuelve a experimentar el malestar-que puede retornar en cierto horror bajo la angustia o en lo ominoso- respecto de su fetalización, en la inmadurez y la desprotección, dehiscencias propias de la discordia primordial, razón por la cual busca un alivio en las imágenes que prolonguen su infancia o juventud. Sin embargo, pese a la búsqueda del efecto balsámico ofrecido por la imagen, ¿qué podría implicar la prolongación de la vida bajo estas condiciones? El hecho es que para Gould existe una especie de optimismo al respecto: el retardo ofrece un mecanismo para retener cualquier rasgo juvenil que convenga a la vida adulta de la descendencia, y así "los rasgos juveniles son un almacén de adaptaciones potenciales para los descendientes" (73).

Por ahora, habremos de retener para nuestros objetivos que, en principio, el ser humano llega a ser lo que es puesto que se encuentra de entrada detenido en su desarrollo -sea por la causa que sea-. Por otra parte, el tiempo parece acecharlo bajo la figura de un animal que ya no podría ser un primate tal como los conocemos, sea que aparezca bajo una especie de figura de ciencia ficción donde el freno hormonal imaginado por Bolk podría soltarse, sea en un tiempo que podríamos suponer alargado gracias al mismo retraso. 


\section{PUNTOS Y CONTRAPUNTOS}

Gould piensa que la fetalización encuentra su significado adaptativo en lo que llama la "evolución social" del hombre, caracterizada por posibilidades de aprendizaje que nos convertirían en un animal que aprende, ventaja de nuestro cerebro y su "notable capacidad para aprender de la experiencia" (73). La fetalización entonces, permitiría dar más tiempo para aprender mejor, retrasando la maduración sexual que se acompañaría de un dato que haría entusiasmarse a cualquier psicólogo del desarrollo: "su ansia adolescente de independencia" (73). Preguntamos: ¿qué sería entonces un adolescente que no quiere ser independiente?, ¿es un neoténico poco adaptado?, ¿prolongaría su infancia porque querría entonces "aprender" más?, ¿o necesita un correctivo para madurar de una vez, sobre todo si su cuerpo ya daría muestras de una sexualidad lista para reproducirse? Como sea, todo esta propuesta de Gould niega la existencia de la sexualidad infantil, caracterizada ciertamente no por la capacidad genital reproductiva, sino por su parcialidad. Luego, "[n]uestros niños se ven atados durante períodos más largos a sus padres, incrementando así la duración de su aprendizaje y fortaleciendo simultáneamente los lazos familiares" (73), argumento que Gould confiesa retomar de John Locke (73).

Si esto es lo que puede pensarse de la fetalización, ¿podemos conjugarlo con el uso que Lacan le da? Pese a la necesidad de despejar el concepto para distinguir el terreno en el cual nos ubica Lacan con la fetalización, queda siempre la tarea de visitar el nuevo territorio construido, es decir, la operación de abducción o de injerto efectuada. Y es que no hay nada que pueda ponerse a cuenta del aprendizaje a partir de las condiciones reales que determinan una imagen dehiscente que se abre así al parasitismo de la palabra; es lo que Lacan refiere en su seminario El yo en la teoría de Freud y en la técnica psicoanalítica cuando se pregunta por la noción de aprendizaje que podría estar implícita en el análisis: "Siempre es el aprendizaje de alguien que lo hará mejor la próxima vez. Y cuando digo que lo hará mejor la próxima vez, significa que tendrá que hacer algo diferente" $(68)^{3}$. Se trataría entonces de una discordancia radical, donde se demuestra que la experiencia humana más profunda carece de un progreso adaptativo que se perfecciona a través de aproximaciones reiteradas: 
Es algo que va por saltos, por brincos, que es siempre la aplicación estrictamente inadecuada de ciertas relaciones simbólicas totales, y quiero decir que implica varias tonalidades, uno con el otro, en las relaciones de uno a otro, que son precisamente las que ya no implican esta especie de [...] La inmixión, por ejemplo, de lo imaginario en lo simbólico, o viceversa (68).

Dado el contexto, podemos pensar que la palabra que falta en esta lección de seminario es algo referido a la "armonía". Es un efecto de la pulsión de muerte que Lacan lee del lado de la palabra y el registro simbólico y que contiene un aspecto ominoso en la medida en que parasita al hombre a la vez que le dona su condición de tal. Si bien Lacan podría estar de acuerdo con el problema de la prolongación del cuidado de los padres hacia la indefensa cría humana en el ejemplo que nos entrega Gould, no lo hace desde el punto de vista de una plenitud supuesta o esperable en esa relación, sino por el contrario, teniendo en cuenta que esa relación es de por sí fallida, tanto por el hecho mismo de la prematuración como por la frágil plenitud imaginaria que ofrece.

Pero la fetalización tiene aún más alcances: nos llevaría a la posibilidad de considerar incluso a los bebés humanos como embriones, quienes nacen así y lo siguen siendo los primeros 9 meses (77). De hecho, las gestaciones debiesen durar al menos un año y medio en el caso de que las mujeres dieran a luz en el momento correcto, lo que permitiría, según la posición que Gould comparte con el zoólogo Adolf Portmann, que los bebés humanos alcanzaran también "los rasgos precoces estándar de otros primates" (77).

Acá destaca con claridad lo que Lacan nunca dejó de mencionar: si el cerebro humano crece más lento y durante un tiempo más largo que el de los otros primates (p. 78), esto comprueba que el chimpancé supera en inteligencia instrumental a la cría humana (El estadio 99), pero es también lo que le permite a esta última, anticiparse en la identificación a la imagen, alcanzando así la vivencia de comprensión de la situación o el aha erlebnis (99). Ahora podemos agregar que la osificación tardía de los huesos acompaña el inacabamiento anatómico del sistema piramidal y la descoordinación motora de los primeros meses descritos por Lacan. Al contrario de la gran mayoría de los mamíferos cuyos cerebros están formados al nacer, el nuestro sigue creciendo a un ritmo fetal después del nacimiento (Gould, Desde 79).

Pero, ¿por qué los bebés humanos son embriones por haber nacido demasiado temprano?, ¿por qué nacen antes de tiempo?, ¿por qué la gestación no se 
encuentra igualmente prolongada como el resto del desarrollo? La manera en la que Gould se explica esta prematuración del nacimiento humano es apelando a su condición dificultosa si la comparamos con otros mamíferos, puesto que es justamente el tamaño del cerebro el que lo entorpece (80). Parece casi una paradoja, ya que, pese a que nace menos desarrollado y expuesto, requiere de esos otros estímulos externos al útero para seguir formando lo que llegará a ser su gran cerebro; por ende, no puede continuar en el útero, o de lo contrario no podrá salir de ahí: es lo que hace declarar a Gould que un niño de 1 año de edad difícilmente podría ser dado a luz por una hembra humana (80). Por lo tanto, aunque el desarrollo cerebral en los mamíferos ocurra ante todo in utero y fetal, el cerebro en éstos no llega a ser muy grande, por lo que no hay problemas a la hora de nacer; en cambio, si el cerebro es más grande, la gestación dura menos y el nacimiento es prematuro para permitir un desarrollo post-natal del cerebro, facilitado además por un crecimiento general retrasado. En resumen, "el nacimiento debe producirse cuando el cerebro tiene sólo un cuarto del tamaño final” (80).

Se trata, al igual que en el caso de la supuesta ventaja de aprendizaje que hacía referencia a Locke, de una explicación por utilidad, aunque agregando ahora la evitación del dolor del nacimiento. Para Gould, el cerebro humano puede actualizar la particularidad de su potencial al quedar expuesto a las condiciones extra-uterinas. Siendo así, ¿cómo separamos aguas con respecto a Lacan? Es que no es lo mismo decir que gracias a que el cerebro puede desarrollarse tempranamente fuera del útero está más abierto al aprendizaje (y que por ende, no hemos alcanzado aún todo nuestro potencial (81)), que plantear que la fetalización, si bien habilita un mundo más rico y polifónico donde la imagen posibilita el valor simbólico de los objetos, imprimiría el sello de un aprendizaje progresivo en aras de una mejor adaptación. Que la inteligencia humana alcance niveles particulares respecto al resto de los mamíferos y que la cría humana logre la hazaña de anticiparse a su insuficiencia, delatan más bien la presencia de un drama que acompañará por siempre al hombre.

Dicho en otros términos: no basta con que Lacan cite biología para convertirse en un biólogo al pie de la letra. Su énfasis en cambio, está en otra parte de la realidad humana. Es así como hemos llegado al nudo central que permitirá la construcción ficticia de una hipótesis explicativa de la relación entre Lacan y Huxley. 


\section{AFTER MANY A SUMMER DIES THE SWANN}

Lacan pudo haber conocido a Huxley cuando el escritor vivió en París hacia fines de los años 20 o en su estadía en el sur de Francia durante la primera mitad de los años 30. La amistad de Huxley con Victoria Ocampo durante ese período (Meyer, Victoria Ocampo. Contra viento y marea) podría fomentar aún más la opción de haberse conocido e intercambiado ideas con Lacan. Huxley emigraría a Estados Unidos el año 1937 luego de su estadía francesa. Sabemos que Viejo muere el cisne es del 39. El hecho de que el mismo Stephen Jay Gould describa el argumento de esta novela al comienzo del ya mencionado El niño como padre del hombre (incluido también en su Ontogenia y filogenia), da cuenta del reconocimiento que un científico puede entregar al uso ficcionado de la fetalización, tanto como ponernos al día respecto del papel jugado por Julian Huxley en el trabajo de documentación. Es así como Gould nos cuenta esta historia que narra a su vez un drama neoténico y por ende, temporal: el hombre que quiere vivir mucho tiempo finalmente tendría que terminar convirtiéndose en simio (67).

La inspiración para Aldous pudo haberle llegado no solo por las temáticas generales trabajadas por Julian, sino también de manera específica por la vía de sus investigaciones en el retardo de las transformaciones en anfibios (Gould, Desde 68). The elements of experimental embryology (1934) contiene una cita que menciona al Axolotl y su permanencia neoténica por falta de metamorfosis, explicando que éstas dependen de ciertas condiciones ambientales externas o internas "en particular la administración de la hormona tiroides" (403). The uniquenes of man (1943) es un trabajo recopilatorio de temáticas abordadas anteriormente, donde la fetalización aparece bajo un rasgo que Julian propone como un subproducto particular en el hombre, a saber, la falta de pelos; dada la indefensión que esto produce, habría servido nada menos que de estímulo para el desarrollo de la inteligencia (13-14).

¿De qué trata Viejo muere el cisne? Un millonario estadounidense llamado Jo Stoyte quiere comprar su inmortalidad. Para esto, contrata un científico, el Doctor Obispo, quien descubre que el conde de Gonister prolonga su vida ingiriendo tripas de pescado, en particular, de carpa. Las páginas finales nos llevan al momento en que Stoyte y Obispo logran entrar en lo del conde. El impacto de un lado y la fascinación por el otro surgen ante lo que observan ahí: "Al otro lado de los barrotes, la luz de la linterna hizo surgir de la oscuridad un breve mundo de formas y colores. En el centro de aquel mundo 
había un hombre sentado al borde de un lecho bajo, que miraba fijamente a la luz, como fascinado. Tenía las piernas desnudas cubiertas de pelo espeso, rústico y rojizo... Sentado con la espalda encorvada, tenía la cabeza echada hacia adelante y como hundida entre los hombros" (Huxley, Viejo muere 291). ¿Qué era lo que veían? "-Un mono fetal que ha tenido tiempo de desarrollarse - logró decir al fin el doctor Obispo -. ¡Es más de lo que me figuraba! -la risa le acometió de nuevo-. ¡Miren qué cara tiene! -profirió jadeante señalando por entre los barrotes" (291). Intempestivamente, surge otra figura con forma de simio, rostro peludo, protuberancia sobre los ojos, mandíbulas inferiores desfiguradas, acrecencias óseas delante de los oídos: "-Es una mujer -dijo Virginia, casi asqueada por la horrible repugnancia que le producía la visión de aquellas ubres colgantes y ajadas" (291). Obispo se ve forzado por Stoyte a responder quiénes son: “-El que lleva la insignia de la orden de la Jarretera - dijo el doctor Obispo, levantando la voz por sobre el tumulto - es el quinto conde de Gonister. Ella es su ama de llaves" (292). La capacidad de alargar la vida -el conde tiene ya más de doscientos años- los había llevado al efecto inevitable de la fetalización, es decir, convertirse finalmente, en monos: "El doctor Obispo continuó hablando. Retardación del proceso de desenvolvimiento... uno de los mecanismos de la evolución... el antropoide era más estúpido cuanto más viejo... la senilidad y el envenenamiento por los esteroles... la flora intestinal de la carpa... el quinto conde se había anticipado a su descubrimiento... nada de envenenamiento por los esteroles, desaparición de la senectud... desaparición de la muerte, tal vez, de no ser por accidente... pero mientras tanto el antropoide llegaba a la madurez...” (292). Y bien, comprobaban así que el asunto daba resultados y Stoyte podía comenzar desde ya a beber el "mejunje": "-¿Cuánto tiempo cree usted que se tarda para que una persona se vuelva así? - dijo en voz baja e indecisa-. Quiero decir... supongo que no sucederá repentinamente... que habrá un largo tiempo durante el cual la persona... bueno, ya sabe usted; durante el que no se producirán alteraciones" (293). La prolongación de la vida no ofrecía aparentemente una imagen tan deseable como Stoyte podría haberlo pensado al contratar al Doctor Obispo. Sin embargo, la tensión de la escena no deja pasar la oportunidad de rematarla con un chiste, puesto que notando que los simios se han retirado en la oscuridad haciendo ruidos que evocan un ritual de apareamiento, y después de sus dudas sobre el tiempo que demorarían en surgir los efectos, Stoyte declara a Obispo que: 
parece como si no lo pasaran mal del todo. Quiero decir a su modo, desde luego. ¿No lo cree usted así, Obispo? -insistió.

El doctor Obispo siguió mirándolo en silencio; luego echó la cabeza para atrás y comenzó a reír nuevamente (293).

Creemos que en una figura como esta se juega el "dramatismo" lacaniano de la dialéctica temporal que se proyecta en historia. El hombre quiere prolongar su vida, lucha contra la muerte que se cuela por la abertura de su nacimiento prematuro, pero a costa de llegar a perder su condición humana. Como nos presenta la novela de Huxley, esta pérdida lo transforma en un animal, pero no simplemente en uno al cual se retorna, sino en uno nuevo: es un monstruo, única condición a la cual se regresa, puesto que la fetalización ya lo había convertido en eso.

En efecto, la monstruosidad es entendida teratológicamente a partir de la fijación o detención del desarrollo. El ejemplo del Axolotl resulta ilustrativo: al frenar su desarrollo que debía convertirlo en Salamandra, se vuelve sin embargo capaz de reproducirse iniciando así una nueva especie. En otros términos, este pequeño monstruo deja de ser un defecto evolutivo para lograr abrir una nueva relación al mundo con su neotenia, tal y como ocurre con la condición humana. El papel de Julian Huxley resulta innegable como influencia en la configuración del argumento de Viejo muere el cisne (Gould, Ontogenia 412).

Pero hay una gracia en la desgracia de la fetalización humana. El historiador alemán Aby Warburg denominó "dialéctica del monstruo" (Didi-Huberman, La imagen 259) a la síntesis temporal de la monstruosidad, puesto que en ellos sobreviven imágenes pasadas, constituyendo condiciones de posibilidad de expresión artística. Podemos leer con esta clave lo que Lacan define como dialéctica temporal: desarrollo detenido, montaje anacrónico donde se invierten y mezclan los tiempos. ¿Y quién era descrita en 1932 como una detenida en su desarrollo? Nada menos que Aimée (Lacan, De la psicosis paranoica en sus relaciones con la personalidad); pero esta detención la convertía en una creadora que probablemente bajo otras circunstancias tal vez no habría despuntado. En ella, el retraso era el paso atrás necesario para dar un salto y su delirio lograba mostrar lo que en la normalidad está desde el inicio detenido: la configuración alienada del yo humano en la imagen del otro. Es muy distinto decir entonces que la dialéctica temporal monstruosa -patente en las psicosis- habilita expresiones artísticas que de otro modo no podrían surgir, a plantear que todo eso es resultado de un aprendizaje permitido por nuestro gran cerebro. 
Seguir al pie de la letra la declaración de amistad que Lacan señala respecto a Huxley, construyendo con ello la hipótesis de una fructífera influencia, nos lleva a poner atención en un dato que aporta mayor verosimilitud. Y es que nada parece indicar que en el estadio del espejo del año 36 Lacan hiciera referencia a un drama como se nos presenta en el 49, en cambio, sí menciona una modificación a su propuesta en 1946, momento donde ya podía estar al tanto de la novela de Huxley. Nos dice en Acerca de la causalidad psíquica: "En verdad, he llevado un poco más lejos mi concepción del sentido existencial del fenómeno, comprendiéndolo en su relación con lo que he denominado prematuración del nacimiento en el hombre, o sea, en otros términos, la incompletud y el "atraso" del desarrollo del neuroeje durante los primeros seis meses" (183). Ese "llevar un poco más lejos" corrobora un énfasis nuevo que tal vez no estaba en las presentaciones anteriores del estadio del espejo, por mucho que la fetalización ya hubiese sido un recurso explicativo, y profundiza así el sentido existencial del mismo. Las líneas que continúan explican que si la preferencia por la imagen y su precipitación a ella están determinadas por esta condición de base, entonces el narcisismo refleja un nudo imaginario donde "yace, en efecto, la relación de la imagen con la tendencia suicida esencialmente expresada por el mito de Narciso" (183). Es en ese suicidio primordial donde habría que leer la intromisión de la pulsión de muerte. Se trata por lo tanto, de cómo la muerte acompaña al hombre durante todo su desarrollo temporal, haciendo de su historia un intento constante por evitarla en sus identificaciones imaginarias, pero aproximándose más a ella en ese mismo gesto que lo arroja hacia una imagen ominosa de sí mismo. El drama de la insuficiencia corporal a la anticipación de la imagen, trae la consecuencia, a modo de rebote, de las fantasías de un cuerpo fragmentado, traducción de ese cuerpo inmaduro y fetalizado cuya completitud finalmente anhelada no podría ser más que ese doble simiesco que lo sigue como un compañero de ruta indeseable.

\section{D.C. AL CODA}

De este modo, extendiendo los alcances de la amistad entre Lacan y Huxley y ficcionando una historia de encuentro posible con intercambio de ideas, no solo inventamos un modo de leer a Lacan, sino que también concluimos en un desciframiento de posición propiamente lacaniana respecto a sus referencias, y en este caso específico, las que atañen a cuestiones biológicas. 
Retomamos lo que Baños Orellana comentaba en torno a la preocupación "recapitulativa" de Lacan cuando se refiere a esos agujeros que son las mamas del ornitorrinco, "biología" nuevamente del objeto $a$ : ella no es la de Ferenzci, haeckeliana y literal, sino la de una literatura irónica que puede corroborarse con la ayuda de Joyce:

Cerca de Joyce porque cuando, en el primer capítulo del Ulises, Buck Mulligan invoca a gritos a la diosa pagana del mar, “ $i T h a ́ l a s s a$ Thálassa!", lo hace únicamente con ánimo de fingir una misa negra y de burlarse de épicas como las de Jenofonte: Joyce está siempre en el plano de la parodia...Lacan no pretende elevar su argumento mítico a explicación científica; en vez de buscar descubrir la filogenia del objeto $a$, quiere escribir la novela infantil del objeto $a$ apelando paródicamente a cartas de nobleza de la Biología (Lacan desdibujado 9).

Casi al modo de los indicadores de dinámica en la escritura musical, la literatura sirve para destacar aspectos que de otro modo quedan relegados a unos aparentes despliegues de erudición y que en el caso de la biología -junto con toda la gama de disciplinas como la zoología o la etología-quedan reemplazados por esquemas $(7,15-16)$ o relegados a un segundo plano respecto a las matemáticas, la topología o la filosofía. Por el contrario, si la biología da cuerpo a los argumentos, la literatura agrega el drama existencial con el cual Lacan profundizó sus presentaciones del estadio del espejo, del mismo modo en que Huxley aprovechó el material ofrecido por su hermano para organizarlo en la ficción de sus novelas. Pero no podríamos notar dicho papel, al menos para lo que corresponde al uso lacaniano de la fetalización, sin la invención de una historia de amistad que no deja de tener elementos reales que la vuelven posible.

No hemos tratado únicamente de mostrar una semejanza o una analogía por puro alcance temático entre ambos autores, donde la fetalización jugaría ese rol, sino que dicha semejanza se enriquece desde el momento en que, con una sola "huella" -el "fósil director" de la amistad entre Lacan y Huxleypodemos suponer una influencia que por muy desconocida que sea, permite despejar una de esas líneas que podrían parecernos representativas de la supuesta ilegibilidad de Lacan. Para ponerlo en palabras más aventuradas, la hiancia de la dialéctica histórico-temporal del drama imaginario puede ser llenada por la ficción fetalizada de Viejo muere el cisne. En suma, la materialidad fecal del objeto a ilustrada con Hiperión a un sátiro (Huxley 1958) en 1963 nos condujo a un momento anterior donde el Huxley del 39 
con su Viejo muere el cisne nos habría hecho "recordar" al Lacan del estadio del espejo en el 49. ¿O es ese Lacan quien habrá sido el que nos recuerde a Huxley? Indiferente resulta si bajo un truco de malabarismo referencial el movimiento es el inverso. En esa zona, el tiempo mismo se trastoca.

\section{BIBLIOGRAFÍA}

Baños Orellana, Jorge. "De cómo la señorita Gélinier transfiguró la lectura lacaniana del caso Dick”. Página Literal, Revista de Psicoanálisis n8-9. San José de Costa Rica, 2008. 116-132.

“Lacan desdibujado". Revista Acheronta 25, 2008. https://www.acheronta.org/ acheronta25/banos.htm

Bolk, Louis. "La genèse de l'humaine". Revue française de psychanalyse, tome XXV, 1961. 243-279.

"Origin of racial characteristics in man". American Journal of Physical Anthropology, Vol. XIII, No. 1. Abril-Junio, 1929. 1-28.

Didi-Huberman, Georges. Ante el tiempo. Historia del arte y anacronismo de la imagen. Buenos Aires: Adriana Hidalgo Editora, 2015.

La imagen superviviente. Historia del arte y tiempo de los fantasmas según Aby Warburg. Madrid: Abada Editores, 2009.

Ferenczi, Sandor. Thálassa, una teoría de la genitalidad. Buenos Aires: Letra Viva, 1983.

Ginzburg, Carlo. El hilo y las huellas. Lo verdadero, lo falso y lo ficticio. Buenos Aires: Fondo de Cultura Económica, 2010.

Gould, Stephen Jay. Desde Darwin. Reflexiones sobre historia natural. Barcelona: Crítica, 2018. Ontogenia y filogenia. La ley fundamental biogenética. Barcelona: Crítica, 2010.

Guillerault, Gérard. Dolto, Lacan y el estadio del espejo. Buenos Aires: Nueva Visión, 2005. Huxley, Aldous. "Hiperión a un sátiro". Adonis y el alfabeto. Buenos Aires: Editorial Sudamericana, 1958.

Viejo muere el cisne. Buenos Aires: Losada, [1939] 1941.

Un mundo feliz. Barcelona: Debolsillo, [1932] 2003.

Huxley, Julian. The elements of experimental embryology. 1934. London: Cambridge University Press, 1963.

The uniqueness of man. 1941. London: Readers Union/Chato \& Windus, 1943.

Lacan, Jacques. "Acerca de la causalidad psíquica”. Escritos 1. 1946. Buenos Aires: Siglo XXI, 2008. 151-190.

“Algunas reflexiones sobre el yo". Verba Volant. Revista de Filosofía y Psicoanálisis, Año 8, No. 1, 2018. 
"El estadio del espejo como formador de la función del yo [je] tal como se nos revela en la experiencia psicoanalítica". Escritos 1. 1949. Buenos Aires: Siglo XXI, 2008. 99-105.

Función y campo de la palabra y el lenguaje. Escritos 1. 1953. Buenos Aires: Siglo XXI, 2008. 231-309. 107-127.

La agresividad en psicoanálisis. Escritos 1. 1948. Buenos Aires: Siglo XXI, 2008.

L'angoisse 19-6-1963. École lacanienne de psychanalyse. http://ecole-lacanienne. net/wp-content/uploads/2016/04/1963.06.19.pdf

"La angustia". Lacantera freudiana. Establecimiento del texto, traducción y notas: Ricardo Rodríguez Ponte. https://www.lacanterafreudiana.com.ar/ lacanterafreudianajaqueslacanseminario $10 . \mathrm{html}$

"La tercera". Intervenciones y textos 2. Buenos Aires: Manantial, 2010. 73-108.

"Le moi dans la théorie de Freud et dans la technique de la psychoanalyse". Staferla. http://staferla.free.fr/S2/S2\%20LE\%20MOI.pdf

"Les formations de l'inconscient". Staferla. http://staferla.free.fr/S5/S5\%20 FORMATIONS\%20.pdf

L'identification, dit "Séminaire IX", prononcé à Sainte-Anne en 1961-1962. Paris: M. Roussan, 1992.

Los complejos familiares en la formación del individuo. Ensayo de análisis de una función en psicología. Otros escritos. 1938. Buenos Aires: Paidós, 2012. 33-96.

"Los escritos técnicos de Freud". El seminario de Jacques Lacan. Libro 1. Buenos Aires: Paidós, 2009.

Variantes de la cura tipo. Escritos 1. 1953-1955. Buenos Aires: Siglo XXI, 2008. 311-346.

Meyer, Doris. Victoria Ocampo. Contra viento y marea. Buenos Aires: Sudamericana, 1979.

Pichon, Édouard. "La famille devant M. Lacan", Revue française de Psychanalyse, tomo xi, $\mathrm{n}^{\circ} 1,1939.107-135$. 